\title{
AUTHOR INDEX Volume 61
}

Adireksombat, Kampon, Fang, Zheng \& Sakellariou, Chris, The Evolution of Gender Wage Differentials in Thailand: 19912007 - An Application of Unconditional Quantile Regression

5 (2016) 1550094

Aloughareh, Iman Rahimi, Ashtiany, Mohsen Ghafory \&

Nasserasadi, Kiarash, An Integrated Methodology for Regional

Macroeconomic Loss Estimation of Earthquake: A Case Study of Tehran

4 (2016) 1550025

Asadullah, M. Niaz, The Effect of Islamic Secondary School Attendance on Academic Achievement

4 (2016) 1550052

Ashtiany, Mohsen Ghafory, see Aloughareh, Iman Rahimi

4 (2016) 1550025

Athukorala, Wasantha, Martin, Wade, Neelawala, Prasad, Rajapaksa, Darshana \& Wilson, Clevo, Impact of Wildfires and Floods on Property Values: A Before and After Analysis

1 (2016) 1640002

Balcılar, Mehmet, Çiftçioğlu, Serhan \& Güngör, Hasan, The Effects of Financial Development on Investment in Turkey

Banerjee, Lopamudra, Catastrophes and Consumption Failure

Bao, Helen X. H. \& Li, Steven Haotong, Overconfidence and Real Estate Research: A Survey of the Literature

4 (2016) 1650015

Chander, Parkash, Public Provision of Private Goods in

Developing Countries

3 (2016) 1640016

Chander, Parkash, Reforming the National Food Security Program

4 (2016) 1671001

Chang, Chun-Ping, see Wen, Jun

5 (2016) 1550065

Chang, Ming-Jen, Half-Life Deviations from Purchasing Power

Parity: Evidence from Pacific Rim Countries

4 (2016) 1650003

Chen, Ku-Hsieh, see Lee, Joe-Ming

5 (2016) 1550102

Chew, Soon Beng \& Tang, Yang, Cost-Benefit Analysis of Union

Membership Without Collective Bargaining Benefits

3 (2016) 1640019

Çiftçioğlu, Serhan, see Balcılar, Mehmet

4 (2016) 1650002

Connolly, Michael, Ronald McKinnon's Contributions to

Economics

2 (2016) 1640024

Dobson, Alexander, see Sgroi, Daniel

3 (2016) 1640015 
Efremidze, Levan, Rutledge, John \& Willett, Thomas D., Capital Flow Surges as Bubbles: Behavioral Finance and McKinnon's Over-Borrowing Syndrome Extended

2 (2016) 1640023

Estrada, Mario Arturo Ruiz, Ndoma, Ibrahim \& Park, Donghyun, The Application of the Minimum Food Security Quota in

Response to a Potential Natural Disaster: The Case of Malaysia 1 (2016) 1640005

Fang, Zheng, see Adireksombat, Kampon

5 (2016) 1550094

Fauli-Oller, Ramon \& Sandonis, Joel, Welfare Effects of

Downstream Mergers and Upstream Market Concentration

Freire, Tiago, How the 1978 Foreign Domestic Workers Law

Increased the Labor Supply of Singaporean Women

Gokcekus, Omer \& Suzuki, Yui, Mixing Washington Consensus

with Beijing Consensus and Corruption in Africa

Güngör, Hasan, see Balc1lar, Mehmet

He, Yin, see Zax, Jeffrey S.

Hill, Hal \& Vidyattama, Yogi, Regional Development Dynamics in Indonesia Before and After the 'Big Bang' Decentralization

Hong, Sung Hyo \& Sullivan, Ryan, The Effects of Subsidies for

Childbearing on Migration and Fertility: Evidence from Korea

Horie, Shinya, see Sanaei, Mohammad

Horioka, Charles Yuji, Is Imbalances and Current Account

Surpluses in Japan: In Memory of Professor Ronald I. McKinnon

Hsu, Yi-Chung \& Lee, Chien-Chiang, Factors Affecting Tax

Evasion: Do Interest Rate and Regional Effects Matter?

Ito, Tadashi \& Okubo, Toshihiro, Product Quality and

Intra-Industry Trade

Jiang, Xu-Zhao, see Liu, Tie-Ying

Kang, Kichun, Keys, Phyllis \& Shin, Yoon S., Free Trade

Agreements and Bridgehead Effect: Evidence from Korea-Chile FTA

5 (2016) 1550098

Kang, Sung-Jin \& Rudolf, Robert, Rising or Falling Inequality in Korea? Population Aging and Generational Trends

Kapur, Basant K., Another Look at Price Instability and Consumer Well-Being: Nondurable and Durable (Housing) Markets

Karim, Azreen \& Noy, Ilan, Poverty and Natural Disasters - A Qualitative Survey of the Empirical Literature - Invited Paper Keys, Phyllis, see Kang, Kichun

Knetsch, Jack L., Reference Dependence and Other Behavioral Findings: The Likelihood of Serious Evaluation and Policy Biases

3 (2016) 1640014

Koerniadi, Hardjo, Krishnamurti, Chandrasekhar \& Tourani-Rad, Alireza, Natural Disasters - Blessings in Disguise?

1 (2016) 1640004

Kotani, Koji, see Shahrier, Shibly

1 (2016) 1640007 
Krishnamurti, Chandrasekhar, see Koerniadi, Hardjo

1 (2016) 1640004

Lee, Chien-Chiang, see Hsu, Yi-Chung

4 (2016) 1550026

Lee, Joe-Ming, Chen, Ku-Hsieh \& Wang, Jying-Nan, The Relation Between Bond Fund Investor Flows and Volatility

Li, Steven Haotong, see Bao, Helen X. H.

Lin, Carl, How Do Immigrants from Taiwan Fare in the U.S. Labor Market?

5 (2016) 1550102

4 (2016) 1650015

5 (2016) 1550057

Lin, Chi-Chih, Can Total Deregulation Be a Better Option Than Partial Deregulation?

Liu, Jiliang, see Wen, Jun

4 (2016) 1550044

5 (2016) 1550065

Liu, Tie-Ying, Su, Chi-Wei \& Jiang, Xu-Zhao, Is China's Urbanization Convergent?

5 (2016) 1550058

4 (2016) 1550063

Mahalik, Mantu Kumar, see Mallick, Hrushikesh

Mallick, Hrushikesh \& Mahalik, Mantu Kumar, Motivating

Factors of Remittances Inflows into Developing Asian

Economies

4 (2016) 1550063

1 (2016) 1640010

1 (2016) 1640008

1 (2016) 1640003

1 (2016) 1640002

Martin, Wade, see Athukorala, Wasantha

Matsuki, Yusuke \& Managi, Shunsuke, The Impact of Natural

Disasters on Manufacturing: Plant-Level Analysis for the Great

Hanshin-Awaji Earthquake

1 (2016) 1640010

4 (2016) 1550025

4 (2016) 1550046

Natsuda, Kaoru, see Otsuka, Kozo

Ndoma, Ibrahim, see Estrada, Mario Arturo Ruiz

1 (2016) 1640005

1 (2016) 1640002

$\mathrm{Ng}$, Yew-Kwang, Welfare-Reducing Growth and Cost-Benefit

Analysis: Essay in Memory of E.J. Mishan

3 (2016) 1640013

Noy, Ilan, see Karim, Azreen

1 (2016) 1640001

4 (2016) 1550106

Okuyama, Yasuhide, Long-Run Effect of a Disaster: Case Study on the Kobe Earthquake - Invited Paper

Oswald, Andrew J., see Sgroi, Daniel

Otsuka, Kozo \& Natsuda, Kaoru, The Determinants of Total Factor

Productivity in the Malaysian Automotive Industry: Are

Government Policies Upgrading Technological Capacity?

1 (2016) 1640009

3 (2016) 1640015

Park, Donghyun, see Estrada, Mario Arturo Ruiz

4 (2016) 1550046

1 (2016) 1640005

2 (2016) 1640028

Phucharoen, Chayanon, see Wiboonchutikula, Paitoon

3 (2016) 1640015

Proto, Eugenio, see Sgroi, Daniel

2 (2016) 1640028

Rajapaksa, Darshana, see Athukorala, Wasantha

1 (2016) 1640002

Rudolf, Robert, see Kang, Sung-Jin

5 (2016) 1550089 
Rutledge, John, see Efremidze, Levan

2 (2016) 1640023

Sakellariou, Chris, see Adireksombat, Kampon

5 (2016) 1550094

Sanaei, Mohammad, Horie, Shinya \& Managi, Shunsuke, Job

Opportunity and Ownership Status: Return Decision After the

Great East Japan Earthquake and Tsunami

1 (2016) 1640008

Sandonis, Joel, see Fauli-Oller, Ramon

Schnabl, Gunther \& Spantig, Kristina, (De)Stabilizing Exchange

Rate Strategies in East Asian Monetary and Economic

Integration

5 (2016) 1550056

Schurer, Stefanie \& Yong, Jongsay, Happiness, Income and

Heterogeneity

2 (2016) 1640021

3 (2016) 1640017

Sgroi, Daniel, Proto, Eugenio, Oswald, Andrew J. \& Dobson,

Alexander, Laboratory Evidence for Emotional Externalities: An

Essay in Honor of EJ Mishan

3 (2016) 1640015

Shahrier, Shibly \& Kotani, Koji, Labor Donation or Money

Donation? Pro-Sociality on Prevention of Natural Disasters

in a Case of Cyclone Aila, Bangladesh

Shin, Yoon S., see Kang, Kichun

Sinclair, Peter, Ezra Mishan, Contrarian and Sage: An

Appreciation

Spantig, Kristina, see Schnabl, Gunther

$\mathrm{Su}$, Chi-Wei, see Liu, Tie-Ying

Sullivan, Ryan, see Hong, Sung Hyo

Suzuki, Yui, see Gokcekus, Omer

Tan, Eu Chye \& Tang, Chor Foon, Economic Growth of Selected

East Asian Countries: A Macroeconomic View of Their

Dependence on the US and Europe

Tan, Seck \& Yu-Hung, Allen Lai, Economic Repercussions of

Extreme Events for an Island Nation: Case of Singapore

Tanaka, Kenta \& Managi, Shunsuke, Impact of a Disaster on Land

Price: Evidence from Fukushima Nuclear Power Plant Accident

Tang, Chor Foon, see Tan, Eu Chye

Tang, Yang, see Chew, Soon Beng

Thampapillai, Dodo J., Ezra Mishan's Cost of Economic Growth:

Evidence from the Entropy of Environmental Capital

Tourani-Rad, Alireza, see Koerniadi, Hardjo

Tower, Edward \& Ye, Yifan Victor, How Taxes and Real Wage

Inflexibility Interact to Make Trade Deficits Addictive: The

Tertiary and Quaternary Burdens of a Transfer

1 (2016) 1640007

5 (2016) 1550098

3 (2016) 1640012

2 (2016) 1640021

5 (2016) 1550058

4 (2016) 1550040

2 (2016) 1640029

5 (2016) 1550066

1 (2016) 1640011

1 (2016) 1640003

5 (2016) 1550066

3 (2016) 1640019

3 (2016) 1640018

1 (2016) 1640004

Vidyattama, Yogi, see Hill, Hal

2 (2016) 1640026

2 (2016) 1640027

Wang, Jying-Nan, see Lee, Joe-Ming

5 (2016) 1550102 
Wen, Jun, Chang, Chun-Ping, Weng, Jia-Hsi \& Liu, Jiliang, Globalization and Real GDP: New Evidence Using Panel Vector Autoregression

5 (2016) 1550065

Weng, Jia-Hsi, see Wen, Jun

5 (2016) 1550065

Wiboonchutikula, Paitoon, Phucharoen, Chayanon \& Pruektanakul, Nuchit, Spillover Effects of Foreign Direct Investment on Domestic Manufacturing Firms in Thailand

2 (2016) 1640028

Willett, Thomas D., see Efremidze, Levan

2 (2016) 1640023

Wilson, Clevo, see Athukorala, Wasantha

1 (2016) 1640002

Yang, Zaigui, Population Aging and Public Pension: The Case of Beijing Analyzed by an OLG Model

4 (2016) 1550045

Ye, Yifan Victor, see Tower, Edward

2 (2016) 1640026

Yie, Myung-Soo \& Yoo, Byoung Hark, The Role of Foreign Debt and Financial Frictions in a Small Open Economy DSGE Model

Yip, Paul S. L., China's Exchange Rate System Reform: Two Potential Mistakes and the Recommended Long-Term System

Yong, Jongsay, see Schurer, Stefanie

Yoo, Byoung Hark, see Yie, Myung-Soo

5 (2016) 1550077

Yu-Hung, Allen Lai, see Tan, Seck

Zax, Jeffrey S. \& He, Yin, The Law of One Price in Chinese Factor Markets

2 (2016) 1640025

3 (2016) 1640017

5 (2016) 1550077

1 (2016) 1640011

4 (2016) 1550101

Zhang, Zhiwen, The Size of Foreign Exchange Reserves and Local Currency Internationalization: Cross-Country Evidence

5 (2016) 1550081 